\section{Critérios Geoelétricos e Água Subterrânea no Campus da UFRRJ, Instituto de Tecnologia de Alimentos, Seropédica, RJ.}

\author{
Leonidas Castro Mello*, Gustavo R. M. de Moraes** e \\ Eduardo Cesar Duarte** \\ ${ }^{*}$ Professor adjunto \\ ${ }^{* *}$ Geólogo
}

\begin{abstract}
RESUMO
Uma campanha geofísica eletroresistivimétrica executada pelo DEGEO/IA/UFRRJ, no entorno do Instituto de Tecnologia de Alimentos foi realizada com a finalidade de escolher a melhor locação para a perfuração de um poço tubular profundo, de forma a se obter água subterrânea que servirá de apoio aos seus projetos de pesquisa.

Como produto final, confeccionou-se um Mapa Isoresistivimétrico do Embasamento Geoelétrico, Bloco Diagrama dessa Superfície Resistivimétrica, Mapa de Espessura do Horizonte de Alteração e de Profundidade ao topo do Embasamento Geoelétrico, assim como um Bloco Diagrama da Superfície desse Embasamento.

Selecionou-se a assinatura elétrica tipo $H$, definidora de uma região resistivimétrica (R3) de 540 ohm.m, associada a uma zona de fraturas do cristalino, que após perfurada, comprova seu potencial aqüífero ao fornecer uma vazão de $9.000 \mathrm{l} / \mathrm{h}$, após teste de 24 horas, com variação de $14 \mathrm{~m}$. entre os níveis dinâmico e $2 \mathrm{~m}$ estático.
\end{abstract}

Palavras chave: sondagens elétricas verticais e água subterrânea

\section{INTRODUÇÃO}

Com o objetivo de fornecer critérios geológicos / geofísicos capazes de identificar condições geohidroestruturais potencialmente fornecedoras de água subterrânea, realizou-se uma campanha de investigação geofísica utilizando-se o método da eletroresistividade, no entorno do Instituto de Tecnologia de Alimentos (IT) dentro do Campus da UFRuralRJ, Município de Seropédica, visando a locação adequada para um poço tubular profundo que servirá de apoio aos seus projetos de pesquisa.

Este trabalho foi executado por uma equipe de geólogos e professor do pelo Departamento de Geociências (DEGEO/IA). Apresenta resultados parciais do Projeto Eletroresistividade no Estado do Rio de Janeiro que consistiram na aquisição e interpretação de Sondagens Elétricas Verticais (SEV's) que permitiram realizar uma caracterização geoelétrica das rochas que compõem o embasamento cristalino da área, bem como a selecionar o local que após perfurado até $35 \mathrm{~m}$. forneceu vazão de 9.000 litros por hora.

\section{METODOLOGIA}

O instrumento geofísico utilizado neste projeto é um eletroresistivímetro ER300 capaz de investigar até $300 \mathrm{~m}$. de profundidade, para a realização de 07 (sete) SEV's com arranjo simétrico tipo Schlumberger, conforme Telford et al. (1990).

O método da eletroresistividade baseia-se na propriedade dos materiais da crosta (solos e rochas) terem sua resistividade decrescida com o aumento do teor de umidade e salinidade da solução saturante. A metodologia de campo consiste em aplicar uma determinada corrente elétrica no solo através de 2 eletrodos de aço, e posteriormente medir a diferença do potencial associado a esta corrente, através de 2 outros eletrodos mais internos e dispostos, no caso, segundo o arranjo de Schlumberger.

O espaçamento entre os eletrodos de corrente que controla a profundidade de investigação $(A B / 2)$ é de $120 \mathrm{~m}$. e as 07 (sete) SEV's perfazem uma área de aproximadamente 02 hectares (20.000 metros quadrados) no entorno do Instituto de Tecnologia de Alimentos (IT).

Conforme descrito em Keller e Frischknecht (1966), utiliza-se o método de encaixe parcial entre as curvas de campo, com curvas padrões e auxiliares, para cálculo das resistividades aparentes, das espessuras e das profundidades dos georesistores identificados. Definidos estes parâmetros, os dados são modelados no programa Surfer V.7 para a confecção dos mapas de isovalores das rochas do cristalino, selecionando-se o método Krigagem como forma de interpolação geoestatístico.

O poço tubular foi perfurado com um equipamento percussivo tipo NSP 325 , atingindo $35 \mathrm{~m}$. de profundidade, com diâmetro final de $150 \mathrm{~mm}$. e vazão de $9.000 \mathrm{l} / \mathrm{h}$, após teste de 24 horas.

\section{CARACTERÍSTICAS GERAIS DA ÁREA DE ESTUDO}

A área estudada está situada no Campus da UFRRJ, Município de Seropédica, Rio de Janeiro, e tem acesso principal pela Avenida Brasil, direção Mangaratiba, onde no cruzamento com o Viaduto dos Cabritos segue-se para o Km 47 da antiga Rodovia Presidente Dutra, ou pela atual Rodovia RJ-SP, via Seropédica.

Inserida no contexto geomorfológico entre a Baixada Fluminense e o Planalto Serrano, sudoeste do Estado do Rio de Janeiro, apresenta topografia relativamente plana, com cotas entre 12 e $15 \mathrm{~m}$. e morfologia suave tipo meia laranja.

A geologia segundo o Mapa do Estado do Rio de Janeiro, escala 1:400.000 (DRM-INPE 1977), é composta por rochas graníticas/gnáissicas do Complexo Litoral Sul-Fluminense, fraturadas e/ou falhas na direção preferencial NE/SW, intrudidas por rochas básicas e alcalinas de idades Mesozóicas (Cretáceo) e Terciárias, respectivamente.

Localmente este conjunto é superposto por solos com horizontes de alteração pedológica tipo $C$ e tipo $B$, que localmente são superpostos por sedimentos Quaternários de origem flúvio lacustre, formando um hiato deposicional localizado. 


\section{RESULTADOS E DISCUSSÃo}

Os dados geofísicos analisados foram correlacionados e associados às observações geológicas de superfície que permitiram a confecção de: A) Mapa Isoresistivimétrico do Embasamento Cristalino (Figura 01), cuja Superfície Isoresistivimétrica pode ser visualizada no Bloco Diagrama (Figura 02); B) Mapa de Profundidade ao Embasamento Cristalino (e de Espessura do Horizonte de Alteração do Cristalino) (Figura 03), cujo topo pode ser visto no Bloco Diagrama (Figura 04)

O Mapa Isoresistivimétrico (Figura 01) do entorno do IT apresenta valores que decrescem de 6.400 ohm.m. a leste da área, para 540 ohm.m., no seu vértice sudoeste, refletindo neste caso, as condições geoelétricas do embasamento cristalino com suas implicações na ocorrência de água subterrânea.

Segundo Mello et. al. (2002), os valores resistivimétricos acima de $2.100 \mathrm{ohm}$.m. indicam rocha sã, sem condições de ceder água subterrânea; valores resistivimétricos entre 1.600-2.100 ohm.m. sugerem rochas fraturadas pouco ou não saturadas, enquanto valores resistivimétricos entre 540-1500 ohm.m., identificam uma zona de fraturas saturadas com direção NW/SE, que sugerem as melhores locações a serem perfuradas.

A Figura 02 apresentada na forma de Bloco Diagrama, permite visualizar a Superfície Resistivimétrica do Embasamento Geoelétrico na área do IT, podendo-se claramente observar na direção N/S, um alto resistivimétrico de 6.400 ohm.m. (lado leste) a 540 ohm.m. (vértice sudoeste).

A transição 3.500 ohm.m. sugere a existência de uma estrutura de subsuperfície, interpretada como contato geológico brusco e/ou uma falha geológica, pois conforme Mello (1994), valores resistivimétricos acima de 4.000 ohm.m. se relacionam às rochas alcalinas intrudidas no embasamento cristalino cujo valor resistivimétrico varia entre $2.100-4.000 \mathrm{ohm} . \mathrm{m}$. quando inalterado.

A Figura 03 apresenta o Mapa de Profundidade ao topo do Embasamento Geoelétrico, esta mesma assinatura geoelétrica também representa o Mapa de Espessura (Isopacas) do Horizonte de Alteração desse embasamento. Observa-se que ao contrário da resistividade, a espessura do horizonte de alteração e profundidade ao embasamento varia, aumentando de $12 \mathrm{~m}$ a oeste para $47 \mathrm{~m}$ no lado leste da área, sugerindo desta maneira, as regiões resistivimétricas mais elevadas (6.400 ohm.m.) que possuem horizonte de alteração mais espessos e, conseqüentemente, maior profundidade até o topo do embasamento geoelétrico, visualizado no Bloco Diagrama da Fig. 04.

Das assinaturas elétricas obtidas, apenas a SEV 01 apresenta assinatura composta tipo $\mathrm{KH}$, enquanto as demais apresentam assinaturas simples tipo $\mathrm{H}$, o que corrobora a possibilidade da existência de uma estrutura planar em subsuperfície de direção N/S, interpretada como um contato geológico brusco e/ou uma falha geológica.

Segundo Nummer et al ( 2003), falhas de orientação NE-SW perfazem $48 \%$ dos lineamentos pertinentes a área de estudo exibindo localmente características compressionais, desta mesma forma, foi possível definir um outro sistema de falhas que perfazem $37 \%$ dos lineamentos NW-SE da referida área.

O ambiente extensional é representado por um sistema de falhas E-W, que eventualmente deslocam sistemas de falhas e fraturas pré-existentes.

Baseado nestes dados pode ser avaliado que, as estruturas localmente caracterizadas por valores resistivimétricos acima de 3.500 ohm.m., e orientação $\mathrm{N}-\mathrm{S}$, podem estar associadas a um ambiente compressional, pois valores resistivimétricos do embasamento cristalino superiores a 1.600 ohm.m estão associados a rochas pouco fraturadas que raramente cedem água subterrânea.

\section{CONCLUSÕES}

$\mathrm{Na}$ área do Instituto de Tecnologia as condições geoelétricas do cristalino, identificadoras de favorabilidade hídrica subterrânea abrangem:

A) Assinatura elétrica composta tipo $\mathrm{KH}$ (SEV 01), o Georesistor R3 = 128 ohm.m. de $30 \mathrm{~m}$. de espessura ocorrem entre $17-47 \mathrm{~m}$. de profundidade, associado ao horizonte de alteração pedológico tipo $\mathrm{C}$ em condições de saturação e confinamento;

B) Assinaturas simples tipo H (SEV's 02 a 07) o Georesistor R2 = 100 ohm.m., ocorrem abaixo da profundidade média de $8 \mathrm{~m}$., possuidor de espessura variando entre $12-28 \mathrm{~m}$, e também associado ao horizonte de alteração tipo C, em condições de saturação, do embasamento cristalino.

C) $\mathrm{O}$ Georesistor $\mathrm{R} 3=540$ - 900 ohm.m. (SEV05/03), ocorre abaixo da profundidade média de $23 \mathrm{~m}$. e identifica uma zona de fratura saturada.

Foi perfurado um poço tubular que atinge $35 \mathrm{~m}$. de profundidade que forneceu após teste bombeamento contínuo durante 24 horas, uma vazão de $9.000 \mathrm{~L} / \mathrm{h}$ e apresentou variação de $14 \mathrm{~m}$. entre os níveis dinâmico e $2 \mathrm{~m}$. para o nível estático, o que demonstra o potencial do aqüífero identificado neste estudo.

\section{REFERÊNCIAS}

Mapa Geológico do Estado do Rio de Janeiro, 1977, escala $1: 400.000$. DRM-INPE,

Keller, G. V.; Frischknecht, F.C., 1966, Electrical Methods, Geophysical Prospecting. Pergamon. London. 517p.

Mello, L. C., 1994, Condições Geoelétricas do Cristalino Fraturado e Possibilidades Hidroestruturais no Município de Queimados, RJ. , VIII Congresso Brasil. Águas Subter., Recife, PE, pg. $226-231$.

Mello, L. C.; Carvalho, L. G.; Moraes, G. R. M., 2002, Geoeletroresistividade e Água Subterrânea em Conservatória, Município de Valença, RJ.

Nummer, A.R.; Miranda, A.W.A.; Monsores, A.L.M.; Castro, D.R.M; Tubbs Filho, D., 2003, Análise Estrutural de Fraturas e falhas aplicada ao mapeamento hidrogeológico em áreas do cristalino: estudo preliminar no Município de Seropédica, RJ. XIII Encontro Nacional Perfuradores de Poços, Petrópolis, Rio de Janeiro: pg. 175 - 186.

Telford, W. M.; Geldart, L. P.; Sheriff, R. E., 1990. Applied Geophysics. Cambridge Univ. Press. Cambridge,770p. 


\section{$\mathbf{N}$}

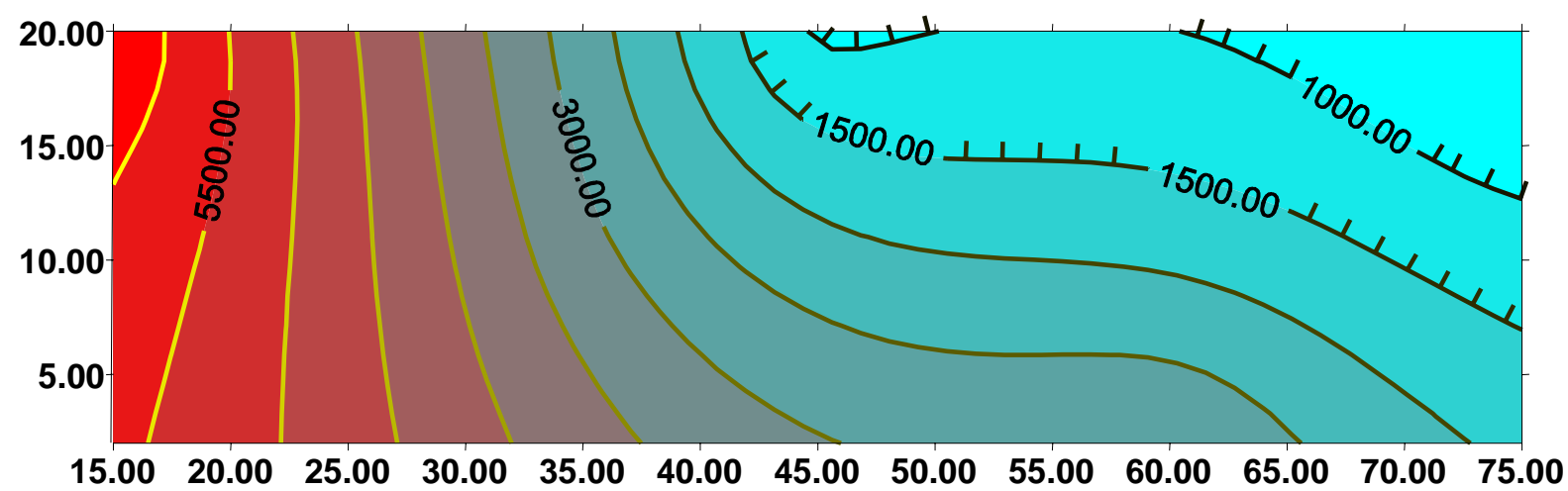

FIGURA 01 - Mapa de Isoresistividade do Embasamento Geoelétrico no entorno do Instituto de Tecnologia, Campus da UFRRJ, Seropédica, RJ. (min 540 - $\max 6.400$ ohm.m)

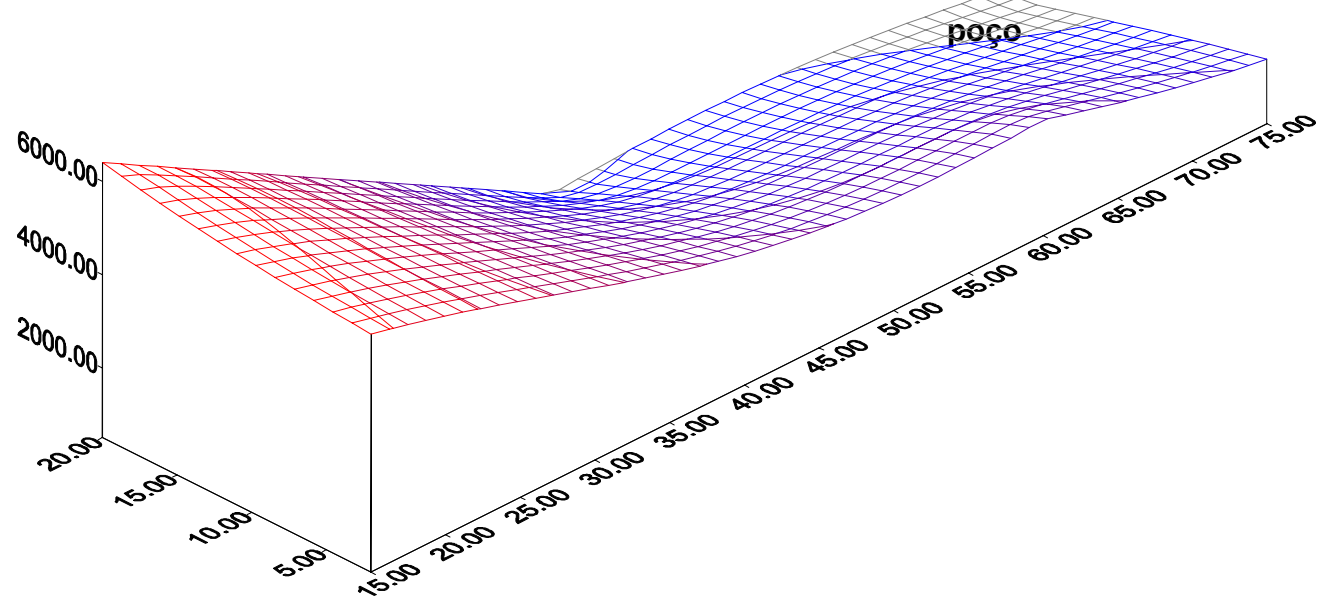

FIGURA 02 - Bloco Diagrama da Superfície Resistivimétrica do embasamento Cristalino no entorno do Instituto de Tecnologia, Campus da UFRRJ, Seropédica, RJ. (min 540 - max 6400 ohm.m) 
I Simpósio da Sociedade Brasileira de Geofísica

$\mathbf{N}$

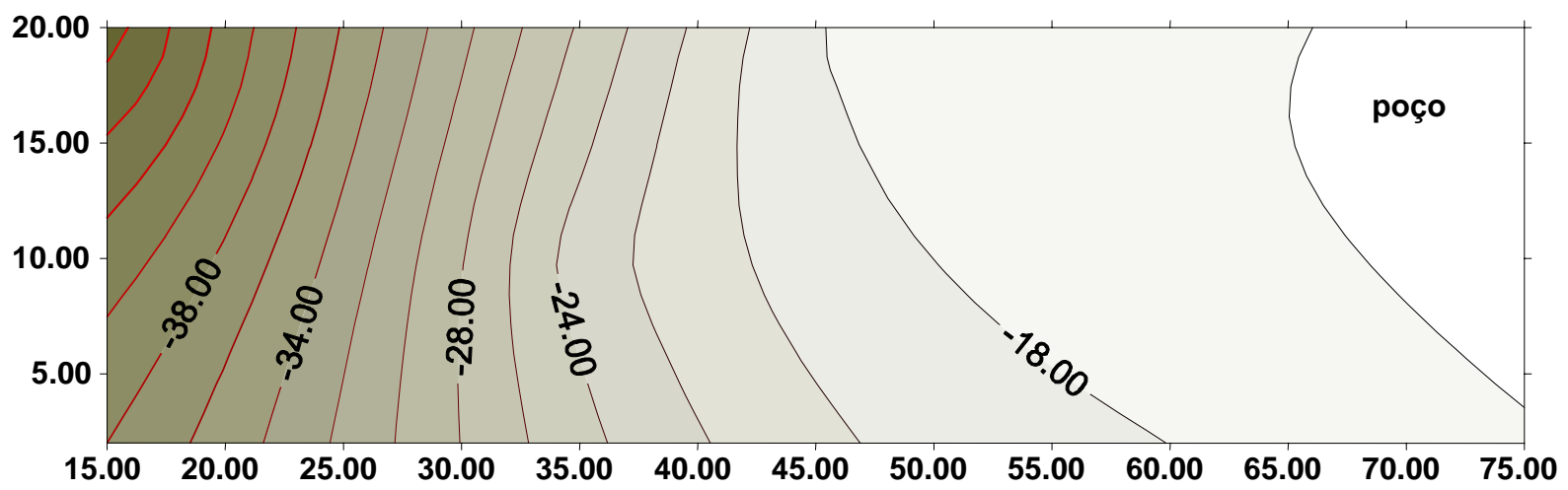

FIGURA 03 - Mapa de Profundidade ao Topo do Embasamento e de Espessura do Horizonte de Alteração, no entorno do Instituto de Tecnologia, Campus da UFRRJ, Seropédica, RJ. (min 12 - max 47m)

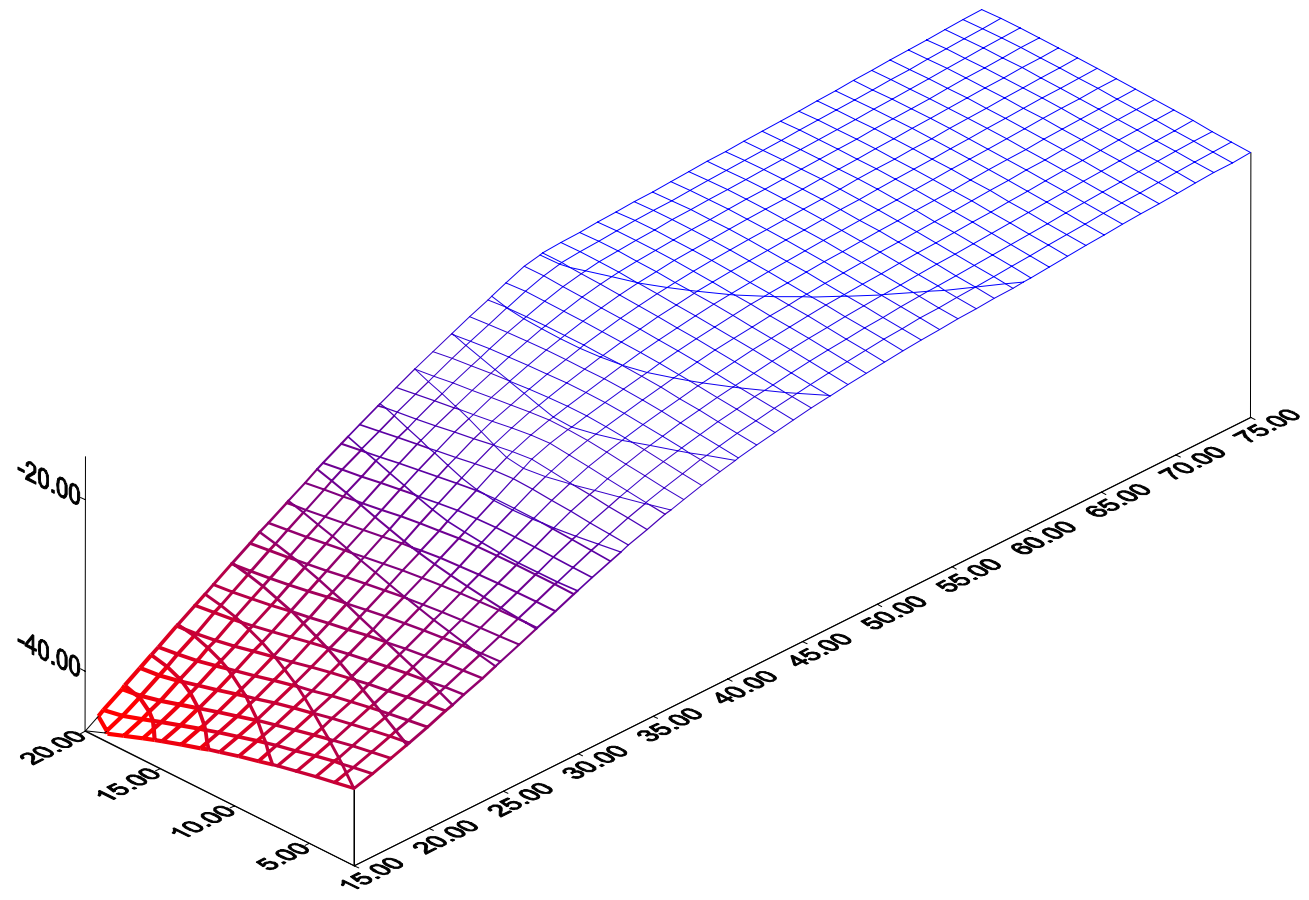

FIGURA 04 - Bloco Diagrama do topo do Embasamento Geoeletrico no entorno do Instituto de Tecnologia, Campus da UFRRJ, Seropédica, RJ. $(\min 12-\max 47 \mathrm{~m})$ 